\title{
A URBANIZAÇÃO DISPERSA DA CIDADE DE UBERLÂNDIA, MINAS GERAIS, BRASIL
}

\author{
The urban dispersion of Uberlândia, MG, Brazil
}

\author{
Leticia Del Grossi Michelotto* \\ Fernando Luíz Araujo Sobrinho**
}

*Acadêmica do PPG em Geografia - UnB - leticiadelgrossi@gmail.com. ** Docente do PPG em Geografia - UnB - flasobrinho@gmail.com.

\author{
Recebido em 13/05/2018. Aceito para publicação em 25/06/2018. \\ Versão online publicada em 10/08/2018 (http://seer.ufrgs.br/paraonde)
}

\begin{abstract}
Resumo: A expansão urbana brasileira apresenta-se ao longo do tempo, de maneira desordenada especialmente nas grandes e médias cidades. Buscou-se nesse trabalho investigar o padrão de crescimento urbano da cidade de Uberlândia, MG, através de revisão bibliográfica, trabalhos de campo e análise de imagens de satélite. Observando-se a paisagem da cidade temos um horizonte amplo marcado pela continuidade, ou seja, o relevo é o primeiro aspecto favorável para a expansão. Porém, o modo de apropriação do espaço urbano na cidade, tem deixado vazios à espera da valorização, fazendo com que a especulação imobiliária antecedesse em alguns locais a própria urbanização, ocasionando a forma de tentáculos, espalhando-se por todas as direções, caracterizando um padrão de crescimento urbano disperso avançando cada vez mais em areas de cerrado.
\end{abstract}

Palavras-chave: Urbanização; Dispersão; Cerrado.

\begin{abstract}
The Brazilian Urban Expansion presents itself over time, more importantly in large and mediumsized cities. In this research we aimed to analyze the urban growth pattern of the city of Uberlândia, MG, through bibliographical review, field work and satellite image analysis. Observing the city landscape there is a wide horizon marked by continuity, that is, the relief is the first favorable aspect for expansion. However, the way how the urban space has been appropriated has left empty spaces waiting for appreciation, where the land speculation acts even before the proper urbanization, causing an expansion of tentacles, spreading by all as directions, characterizing a pattern of dispersed urban growth.
\end{abstract}

Key-words: Urbanization; Dispersion; Cerrado.

\section{Introdução}

Exemplo de cidade média, com aproximadamente 700 mil habitantes e importante rede do sudeste brasileiro, a cidade de Uberlândia, MG tem sido retratada no tempo e no espaço por vários pesquisadores e não é diferente de outras cidades brasileiras com forte crescimento urbano desde as últimas décadas. Qualquer observador atento das questões urbanas percebe que alguns setores da cidade registram esse fato de forma muito acentuada.

Atualmente, é a cidade mais importante da região do Triângulo Mineiro e continua apresentando um rápido e intenso desenvolvimento econômico em consequência da expansão industrial. Destacase na agroindústria (grãos, carne, frutas, vegetais e laticínios), assim como a biotecnologia e comunicação. No final dos anos 2000, novas frentes de expansão urbana avançam para além dos limites do perímetro urbano, especialmente nas áreas leste e sul

Dessa forma, a escolha do objeto de estudo e da área de aplicação se justificam pela atualidade da temática e pela dinâmica atual do espaço em transformação. Tem-se como recorte temporal, do ano 
2008 até início de 2017, período marcado pelo intenso processo de urbanização das áreas periurbanas da cidade. Essa urbanização é tida tanto como similar no aspecto locacional, ocupando áreas da cidade que até então eram fruto da especulação imobiliária de pequenos grupos das elites locais, quanto diferente pelo padrão e características habitacionais.

Diante desse panorama de ocupação dispersa e diversa (do ponto de vista social) dessas areas, incluem-se a abertura de vias, interligações no sistema de anel viário atendendo aos interesses dos agentes produtores e modeladores do espaço urbano e que também contribuem para a expansão do perímetro urbano e as mudanças na paisagem urbana periférica.

A metodologia utilizada na pesquisa baseou-se em revisão bibliográfica sobre o crescimento urbano da cidade ao longo do tempo, de trabalhos de campo os quais deram importantes contribuições para a pesquisa e também pela análise de imagens de satélite e mapas do município.

\section{Desenvolvimento}

Para a análise da relação entre dispersão urbana e o padrão de crescimento de Uberlândia, realizou-se primeiramente uma revisão da literatura sobre as temáticas para que, posteriormente, pudéssemos, através de imagens de satélite e trabalhos de campo, identificar características desse padrão de crescimento urbano.

\subsection{Características da dispersão urbana}

Duas facetas do crescimento urbano, tamanho populacional e os padrões de expansão, têm recebido desigual atenção nas pesquisas relacionadas a esse tema. Segundo Ojima (2010), o desafio atual não se concentra em mensurar o crescimento urbano, mas as formas de como o espaço é consumido em um mundo cada vez mais globalizado. Ainda Segundo Ojima (2007), as dimensões mais recorrentes na literatura sobre propostas metodológicas para o estudo da dispersão urbana, são: densidade, fragmentação, orientação e centralidade. 0 autor analisou cada uma dessas dimensões separadamente. Para a dimensão da densidade, por exemplo, ele cita o uso de imagens de satélite para o estudo da expansão urbana como prática recorrente de mensuração e também a análise das densidades populacional e domiciliar que permitem verificar as distintas condições em termos de densidade urbana.

O urban sprawl ou espraiamento urbano/dispersão urbana é caracterizado por um padrão de baixa densidade de ocupação, não desejável por muitos planejadores urbanos. Esse tipo de crescimento é caracterizado pelo avanço da mancha urbana a partir dos eixos principais de acesso em direção às bordas ou franjas da cidade. A ocupação normalmente é por condomínios horizontais de alto e médio padrão e, também, por conjuntos habitacionais populares.

Alguns efeitos nocivos são verificados quando ocorre esse tipo de expansão urbana, como danos ambientais pelo processo de ocupação de áreas de fragilidade ambiental, desvalorização da área central por criar novos vetores de comércio, aumento da desigualdade social e espacial, levando os pobres cada vez mais distantes das oportunidades do meio urbano (SILVEIRA; RIBEIRO, 2006).

Considerando que o espaço da cidade é estruturado fundamentalmente pelas condições de deslocamento das pessoas - como portadoras da força de trabalho e como consumidoras destacam-se os efeitos negativos do modelo de expansão em foco, no que diz respeito à relação (biunívoca) conflituosa entre a acessibilidade, englobando as oportunidades urbanas, e a ocupação e o uso da terra urbana. (SILVEIRA; RIBEIRO, 2006, s.n.) 
VILLAÇA (2001), analisa esse movimento das classes menos favorecidas para as periferias na cidade. Dessa forma, as classes de maior poder aquisitivo vão ocupando os espaços que lhes convém, gerando assim formas diferenciadas de apropriação do espaço urbano pela segregação espacial imposta as classes menos favorecidas.

Outro aspecto importante a considerar é que o avanço da urbanização no mundo de um modo geral tem ignorado a capacidade de suporte do meio ambiente, necessitando de uma mudança nos padrões culturais, de consumo e governabilidade. É nas cidades que as relações econômicas, sociais, culturais e ambientais são intensas, desiguais e contraditórias.

SPOSITO (2003) considera sob o aspecto ambiental urbano que:

Na relação entre o urbano e o meio ambiente caberia como linha de raciocínio entender que se o ambiental é a síntese, ainda que contraditória, entre o natural e o social, o embate seria, antes, entre o social e o político, sendo a questão ambiental, nas cidades, uma das expressões mais completas desse conflito (SPOSITO, 2003, p. 295).

\subsection{Uberlândia no contexto da urbanização}

Nos últimos quarenta anos, foram significativas as mudanças na dinâmica urbana e demográfica que podem ser verificadas através da análise da evolução das taxas de crescimento populacional, do grau de urbanização e dos índices de densidade populacional, ilustrados nas tabelas 1 e 2.0 fato mais marcante do processo de urbanização é dado pelos movimentos migratórios, ou seja, saída da população das pequenas cidades da região, saída da população do campo em razão da modernização agropecuária e pela chegada de imigrantes de outros estados.

Tabela 1 - Taxa de Crescimento Uberlândia/Anos

\begin{tabular}{ccc}
\hline Ano & Estimativa/Uberlândia & Taxa de Crescimento Anual \\
\hline $\mathbf{2 0 0 5}$ & 585.262 & 2,67 \\
$\mathbf{2 0 0 6}$ & 600.368 & 2,581 \\
$\mathbf{2 0 1 0}$ & 604.013 & 1,3327 \\
\hline
\end{tabular}

Fonte: IBGE - Secretaria de Planejamento e Desenvolvimento Urbano, 2010.

Tabela 2 - Taxa de Crescimento Uberlândia/Anos

\begin{tabular}{ccccc}
\hline & \multicolumn{3}{c}{ Uberlândia } \\
\hline $\mathbf{1 9 9 6}$ & Censo & & \multicolumn{2}{c}{ Taxa de Crescimento } \\
438.986 & $\mathbf{2 0 0 0}$ & $\mathbf{2 0 1 0}$ & Anual & Período \\
& 501.214 & 604.103 & $2,68 \%$ & $37,61 \%$ \\
\hline
\end{tabular}

Fonte: IBGE - Contagem Populacional 1996 e Censos 2000/2010.

O expressivo crescimento da população urbana elevou o índice urbano com melhores condições de vida e oportunidades de trabalho. Uberlândia apresenta, segundo o censo de 2010, 97,6\% de população urbana. Esses dados se traduzem na densidade demográfica urbana que apresenta 123,88 Hab./Km em Uberlândia.

Os loteamentos para além da área central, conforme observados por Del Grossi (1991), ocupavam na década de 1960,1/3 do perímetro urbano. É na década de 1980 que os setores sul e sudoeste são especialmente ampliados, tendência essa que vai continuar nas décadas seguintes, conjugando nesses locais condomínios horizontais para a classe A e B e loteamentos populares. 
Um outro salto de ocupação urbana se intensifica no início dos anos 2000 e se estende até os dias atuais, marcado pela vinda de grandes incorporadoras imobiliárias como o grupo Alphaville e Cyrela, além de grandes obras de habitações populares que ocupam áreas cada vez mais próximas às bordas do perímetro urbano, ocupando não só os setores sul e sudoeste, mas também o setor leste da cidade.

Esses novos loteamentos trazem em sua gênese demandas urbanas tais como transporte coletivo, infraestrutura, asfaltamento, além do aumento crescente das despesas públicas. Conforme Sposito (2010) descreveu, os agentes de produção do espaço urbano procuram criar novas demandas agregando novas qualidades, ou seja, uma sucessão de loteamentos imobiliários de modo a gerar a substituição de um produto imobiliário por outro e também, na construção de imóveis com padrões diferentes em todo o espaço urbano. Através das imagens de satélite organizadas na Figura 1 é possível analisar a evolução da apropriação do espaço de Uberlândia entre 1994 e 2016.
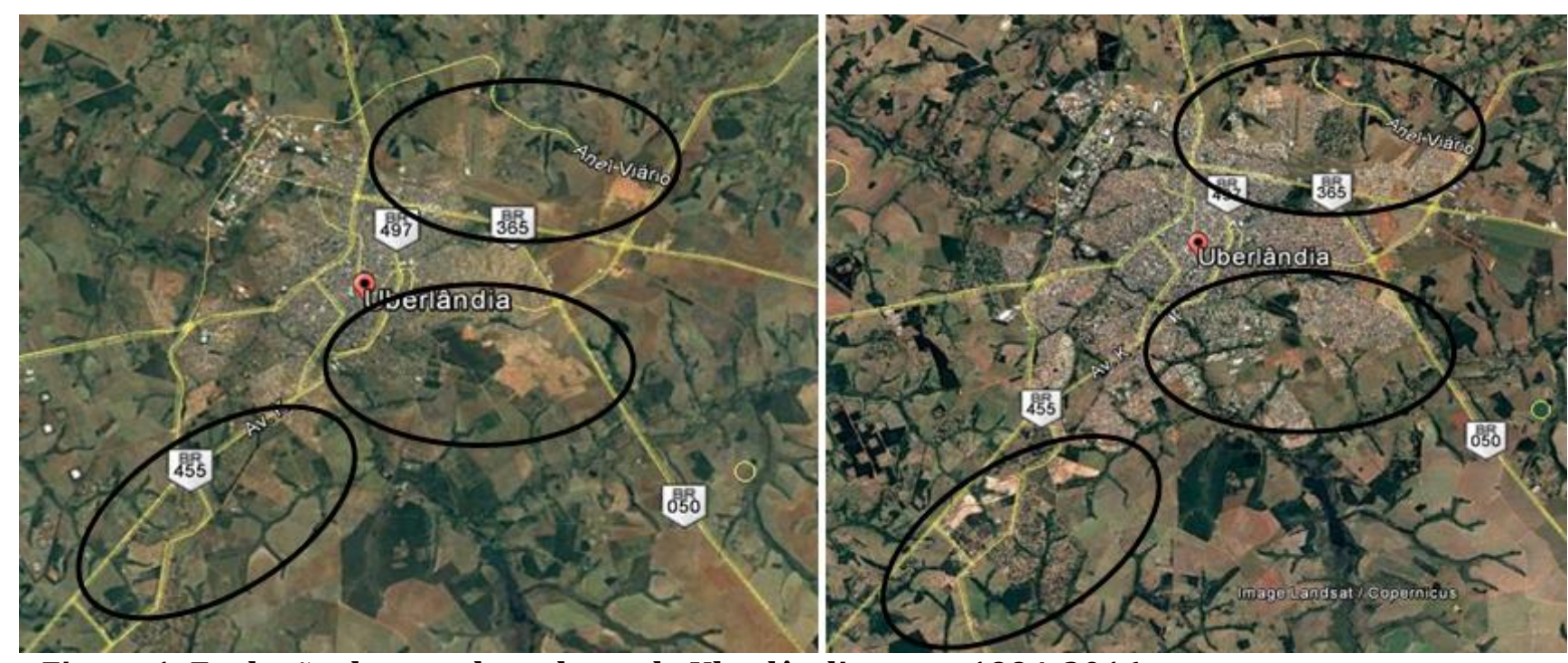

Figura 1: Evolução da mancha urbana de Uberlândia entre 1994-2016

Fonte Google Earth.

Org. Autor, 2017.

Observamos na figura da esquerda, o espaço urbano em 1994 e na da direita, em 2016. Nota-se o crescimento da cidade em todas as direções, mas especialmente nos setores sul e leste.

MOURA (2008), em sua pesquisa sobre condomínios fechados e loteamentos no setor leste de Uberlândia, deixou algumas questões futuras entre elas, se continuariam a expandir e qual seria a trajetória dos investimentos imobiliários nos anos seguintes.

A essas questões é possível constatar que os condomínios e loteamentos continuam se expandindo e novos empreendimentos e agentes são evidentes, como o bairro Bosque dos Buritis, condomínios Alphavile 1 e 2 e o adensamento do bairro planejado Granja Marileusa. Na Figura 2, podemos observar pela imagem de satélite a evolução da ocupação do solo da zona leste entre os anos de 2008 e 2014. Em vermelho, temos condomínios horizontais de alto padrão (Alphaville 1 e Chácaras Paradiso) e também area do bairro Granja Marileusa (MICHELOTTO, 2014). Em roxo, condomínios horizontais de médio e baixo padrão e de alta densidade populacional. São 914 casas distribuídas nos condomínios Terra Nova 1, 2 e 3. 

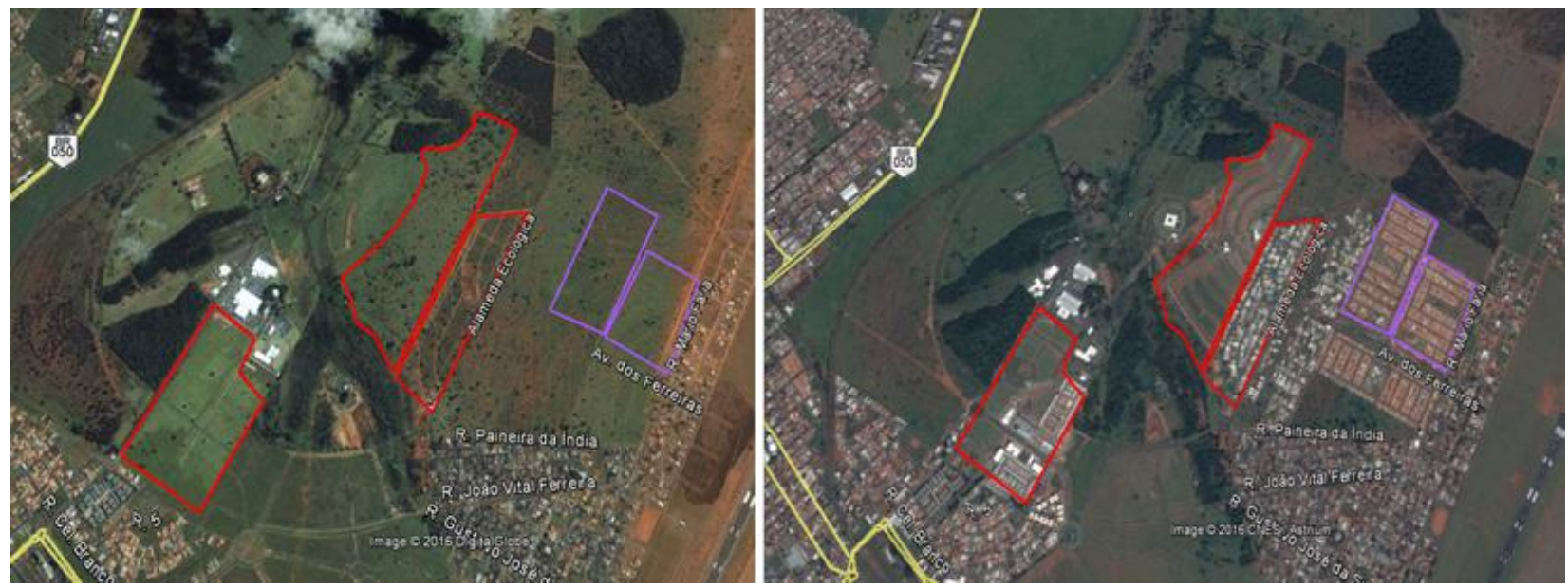

Figura 2: Evolução da ocupação do solo setor Leste de Uberlândia, MG (2008-2014)

Fonte Google Earth.

Org. MICHELOTTO, 2014.

Na Figura 3, podemos observar a implantação do Alphaville 2, ao lado do Alphaville 1, bem próximo ao anel viário e BR 050.

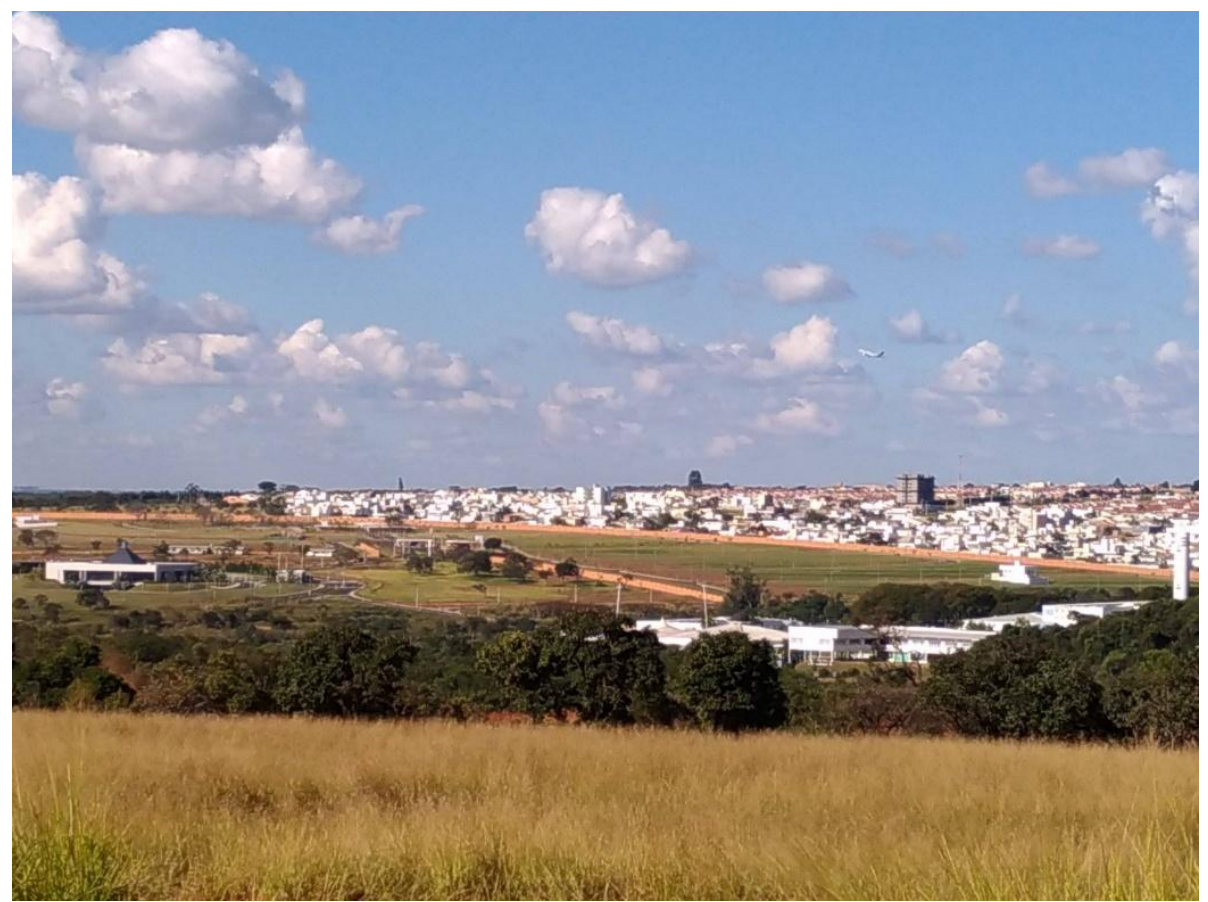

Figura 3: Condomínios Alphavile 1 e 2

Fonte: autor, 2017.

Já na Figura 4, no outro extremo da cidade, temos os conjuntos habitacionais de moradias populares, Pequis e Monte Hebron. Essas areas foram recém incorporadas ao perímetro e urbano favorecendo agentes imobiliários. Além disso, esses residenciais de alta densidade populacional com capacidade para abrigar uma população estimada em 15 mil habitantes, ocupam uma área de fragilidade ambiental e que merecem atenção por parte do poder público. 


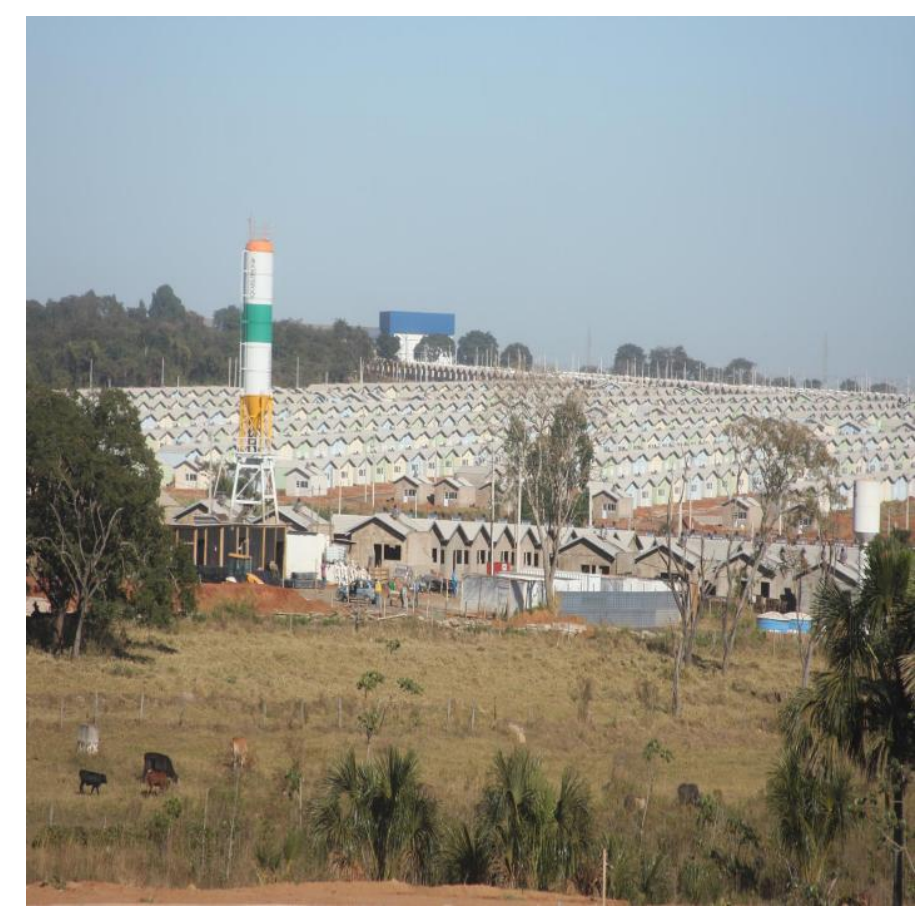

Figura 4: Vista do Residencial Pequis, Uberlandia-MG

Fonte: autor, 2017.

\section{Conclusão}

Para concluir, podemos tecer algumas considerações sobre a expansão urbana dispersa e diversa de Uberlândia.

Vimos que o modo como a expansão urbana avança para as bordas da cidade não é resultado de pequenos construtores ou proprietários de lotes, mas de grandes agentes imobiliários como também do poder público, que participam para a sua infraestrutura e imprimem no espaço uma produção em larga escala, característica presente na dinâmica atual da cidade. 0 adensamento dessas novas areas tem provocado uma dispersão cada vez mais acentuada do território ocupando e desmatando extensas areas de cerrado.

Características como processo de ocupação, sítio urbano, atividade econômica, inserção regional, dentre outros devem ser considerados e reconhecidos como as especificidades de cada cidade para que ocorram mudanças estruturais e sociais.

Ao se pensar o futuro das cidades, devemos nos atentar para um planejamento urbano que integre os desafios ambientais, sociais, econômicos e de governabilidade.

\section{Referências}

DEL GROSSI, S. R. De Uberabinha a Uberlândia. Os caminhos da natureza. Tese (Tese de doutorado). Faculdade de Filosofia, Letras e Ciências Humanas. Departamento de Geografia. Universidade de São Paulo, 1991.

MICHELOTTO, L. D. G. Expansão urbana e sustentabilidade: análise do setor leste de Uberlândia, MG. Dissertação de mestrado. Universidade Federal de Uberlândia, Instituto de Geografia, 2014. 
MOURA, G. G. Condomínios horizontais/loteamentos fechados e a vizinhança (in)desejada: um estudo em Uberlândia/MG. Tese (tese de doutorado). Instituto de Geografia. Universidade Federal de Uberlândia, 2008.

OJIMA, R. Dimensões da urbanização dispersa e uma proposta metodológica para estudos comparativos. In: R. bras. Est. Pop., São Paulo, v. 24, n. 2, p. 277-300, jul./dez. 2007.

OJIMA, R. Análise comparativa da dispersão urbana nas aglomerações urbanas brasileiras: elementos teóricos e metodológicos para o planejamento urbano e ambiental. Tese (tese de doutorado). Instituto de Filosofia e Ciências Humanas da Universidade Estadual de Campinas, Universidade Estadual de Campinas, SP, 2007.

SILVEIRA, J; RIBEIRO, E. O fenômeno do sprawling urbano e a dinâmica da segregação socioespacial. In Revista de Arquitetura e Urbanismo. Disponível em <http://au.pini.com.br/arquiteturaurbanismo/185/o-fenomeno-do-sprawling-urbano-por-edson-leite-ribeiro-e-149628-1.aspx> Acesso em 10/05/2017.

SOARES, B. R. Uberlândia: da cidade jardim ao portal do cerrado - imagens e representações no Triângulo Mineiro. 1995. 347f. Tese (doutorado em Geografia Humana) - Departamento de Geografia, Universidade de São Paulo, São Paulo. 1995.

SOARES, B. R. et al. Dinâmica urbana na bacia do rio Araguari - 1970-2000. In: LIMA, Samuel do C.; SANTOS, Rossevelt J. (org). Gestão ambiental na bacia do rio Araguari: rumo ao desenvolvimento sustentável. Brasília: CNPq, 2004. p. 125-162.

SPOSITO, M. E. B. Sobre o debate em torno das questões ambientais e sociais no urbano. In: CARLOS, A. F. A.; LEMOS A. I. G. (Orgs.). Dilemas urbanos: novas abordagens sobre a cidade. 1. ed. São Paulo: Contexto, 2003, v. 1, p. 358-363.

VILAÇA, F. Espaço intra-urbano no Brasil. São Paulo: Studio Nobel, 1998. 